Young Scholar's Contribution

\title{
RETROSPECTION OF THE ARCHITECTURAL CHARACTERISTICS OF MITHA RAM HOSTEL IN KARACHI
}

\author{
Ar. Tania Ali Soomro
}

\begin{abstract}
Underlining the architectural characterization of a historic edifice is an essential tool towards its preservation and needs to be seen critically. Though the concept of heritage preservation is relatively a new phenomenon, yet it is widely accepted due to the recognition of heritage as an economic asset. Historic buildings are the strength of a nation that helps in building its identity as they reflect on the past, history and culture of a nation. For instance in Pakistan the sites such as Moen-jo-Daro and Thakh-i-Bahi are cherished, as they signify the value of empires that once dwelled, hence expresses a strong nostalgic value. Though these examples are on the World Heritage list, thus they have enough protection and monitoring system, but the rest of the national or provincial level historic properties suffer greatly due to the rapid transformation, resulting from an ever increasing commercialization pressure. This pressure directly and indirectly affects the heritage enclaves. Historic buildings specifically are subjected to destruction, deteriorating to a state in which they are not able to justify the purpose for which they were primarily built. Mitha Ram Hostel in Karachi is one such example, which is still surviving and is operative, but has had a change of function. Moreover there is lack of permanent institutional setup or any sort of partnership with the government, hence not many conservation exercises are seen in the country (Mumtaz, 2017). Apart from the institutional setup, community being the primary stakeholder, plays a vital role in safeguarding the heritage. But regrettably majority of the community defies any interest in conserving these buildings. Some of the restoration measures stop damage to heritage buildings but are not satisfactory to prolong the lifespan of the buildings. Thus, a need for a proper conservation plan cannot be denied. Mitha Ram Hostel, is an exceptional piece of architectural marvel that the city of Karachi has as a reminiscent of the colonial past. The hostel structure was built during the phase of 1894 and 1901 in pre-partition era, hence British colonial features are predominantly visible in the building. The structure was built to facilitate the out stationed pupils of the Dayaram Jethumal (DJ) Science College and was designed by Architect James Strachan who is credited with designing the most important structures the city offers at present day. The Serai Quarter, where this hostel is located, represents the old prevailing colonial architectural heritage in Karachi and holds over two hundred protected properties, but the enormity of this hostel surpasses the rest.

The present state of conservation of the building is partly maintained, however, it was notified as a protected heritage on the provincial level by the Department of Culture, Government of Sindh, having enlistment number 1995-152. This provided it with an addition protection. This, along with the Jinnah Courts Hostel has been taken over by the law enforcement agencies, depriving the key educational institutions of their asset of edification. This research paper inspects the distinct architectural character of the hostel structure, and aims to analyze the diminishing hostel culture within the Quarter. The paper concludes with the concern of conserving the hostel structure as a forgotten architectural heritage of Pakistan, which otherwise is highly neglected in the third world context.
\end{abstract}

